\title{
Immunotoxicity of zinc oxide nanoparticles with different size and electrostatic charge
}

This article was published in the following Dove Press journal:

International Journal of Nanomedicine

15 December 2014

Number of times this article has been viewed

\section{Cheol-Su Kim ${ }^{1, *}$ Hai-Duong Nguyen ${ }^{1, *}$ \\ Rosa Mistica Ignacio ${ }^{2}$ Jae-Hyun Kim' Hyeon-Cheol Cho' Eun Ho Maeng ${ }^{3}$ Yu-Ri Kim ${ }^{4}$ Meyoung-Kon $\mathrm{Kim}^{4}$ Bae-Keun Park ${ }^{5}$ Soo-Ki Kim ${ }^{1,5}$ \\ 'Department of Microbiology, Wonju College of Medicine, Yonsei University, Wonju-si, Gangwon-do, Republic of Korea; ${ }^{2}$ Department of Environmental Medical Biology, Wonju College of Medicine, Yonsei University, Wonju-si, Gangwon-do, Republic of Korea; ${ }^{3}$ Healthcare Laboratory, Medical Device Evaluation Team, Korea Testing and Research Institute, Gimpo-si, Gyeonggi-do, Republic of Korea; ${ }^{4}$ Department of Biochemistry and Molecular Biology, Medical School and College, Korea University, Seoul, Republic of Korea; ${ }^{5}$ nstitute of Lifestyle Medicine, Wonju College of Medicine, Yonsei University, Wonju-si, Gangwon-do, Republic of Korea}

*These authors contributed equally to this work

Correspondence: Soo-Ki Kim Department of Microbiology, Wonju College of Medicine, Yonsei University, Wonju-si, Gangwon-do, 220-70I, Republic of Korea

Tel $+82 \quad 1033708446$

Fax +820337324446

Email kim6@yonsei.ac.kr
Abstract: While zinc oxide ( $\mathrm{ZnO}$ ) nanoparticles (NPs) have been recognized to have promising applications in biomedicine, their immunotoxicity has been inconsistent and even contradictory. To address this issue, we investigated whether ZnO NPs with different size (20 or $100 \mathrm{~nm}$ ) and electrostatic charge (positive or negative) would cause immunotoxicity in vitro and in vivo, and explored their underlying molecular mechanism. Using Raw 264.7 cell line, we examined the immunotoxicity mechanism of ZnO NPs as cell viability. We found that in a cell viability assay, ZnO NPs with different size and charge could induce differential cytotoxicity to Raw 264.7 cells. Specifically, the positively charged ZnO NPs exerted higher cytotoxicity than the negatively charged ones. Next, to gauge systemic immunotoxicity, we assessed immune responses of C57BL/6 mice after oral administration of $750 \mathrm{mg} / \mathrm{kg} /$ day dose of ZnO NPs for 2 weeks. In parallel, $\mathrm{ZnO}$ NPs did not alter the cell-mediated immune response in mice but suppressed innate immunity such as natural killer cell activity. The $\mathrm{CD} 4^{+} / \mathrm{CD} 8^{+}$ratio, a marker for matured T-cells was slightly reduced, which implies the alteration of immune status induced by ZnO NPs. Accordingly, nitric oxide production from splenocyte culture supernatant in $\mathrm{ZnO} \mathrm{NP}$-fed mice was lower than control. Consistently, serum levels of pro/anti-inflammatory (interleukin [IL]-1 $\beta$, tumor necrosis factor- $\alpha$, and IL-10) and T helper- 1 cytokines (interferon- $\gamma$ and IL-12p70) in $\mathrm{ZnO}$ NP-fed mice were significantly suppressed. Collectively, our results indicate that different sized and charged ZnO NPs would cause in vitro and in vivo immunotoxicity, of which nature is an immunosuppression.

Keywords: immunosuppression, cytokine, $\mathrm{ZnO}$, immune response, cytotoxicity, innate immunity

\section{Introduction}

Nanotechnology has enabled nanoparticles (NPs) to be designed at the molecular (nanometer) level. Thus, NPs have received the tremendous advantage of their small size, novel physicochemical properties, as well as their interactions with biological systems. In particular, inorganic NPs with metal oxides have been pre-clinically employed for diagnostic and therapeutic use in biomedicine. ${ }^{1-4}$ Of these metal oxides, zinc oxide $(\mathrm{ZnO}) \mathrm{NPs}$ have received considerable attention, with a promising biological application for drug delivery and cancer therapy ${ }^{5-7}$ due to their great photo-catalytic and photo-oxidizing ability against chemical and biological species.

Despite the potential biomedical application of $\mathrm{ZnO} N \mathrm{NP}$, biohazards and toxicities of $\mathrm{ZnO}$ NPs remain unclear. Of these toxicities, the effects of ZnO NPs on the immune system are poorly documented. Here, immunotoxicity is defined as the adverse effects on the immune system such as hypersensitivity, chronic inflammation, immunosuppression, immunostimulation, and autoimmunity. Much evidence suggests that $\mathrm{ZnO}$ 
NPs would function as immunotoxicants. ${ }^{8-11} \mathrm{ZnO}$ NPs have unique physicochemical properties, therefore, they could easily access several immune tissues and cells through various routines such as inhalation, ingestion, skin uptake, and injection. $\mathrm{ZnO} \mathrm{NP}$ oral administration could cause severe damage to heart, lung, liver, and kidney, ${ }^{12}$ consequently leading to inflammation. In addition, in vitro exposure of $\mathrm{ZnO}$ leads to generation of reactive oxygen species (ROS), upregulation of genes involved in apoptosis, and cell death in human keratinocyte HaCaT cells. ${ }^{13,14}$ Likewise, profuse release of inflammatory mediators induced by $\mathrm{ZnO} \mathrm{NPs}{ }^{15,16}$ may result in immune stimulation or aggravation of immune diseases ${ }^{17}$ or even break down T helper (Th)-1/Th-2 balance. ${ }^{18}$

It is well known that immunotoxicity of NPs is intimately linked to oxidative stress. For instance, the toxicity of $\mathrm{ZnO}$ NPs to immune cells is involved in ROS generation. ${ }^{19-22}$ The high production of superoxide in mitochondria reduces the mitochondrial membrane potential, ${ }^{23}$ causing cell cycle arrest at $\mathrm{S} / \mathrm{G} 2$ phase, ${ }^{24}$ and increases the ratio of $\mathrm{Bax} / \mathrm{Bcl}-2$, leading to the mitochondria-mediated pathway involved in apoptosis. ${ }^{25}$ However, the mechanism of immunotoxicity of $\mathrm{ZnO}$ NPs in relation to oxidative stress is unclear.

To trigger immunotoxicity, several traits or features of NPs are essential. ${ }^{26}$ Emerging evidence implies that the toxicity of $\mathrm{ZnO}$ NPs could be affected by size and/or electrostatic charge. ${ }^{27,28}$ For instance, an increase of ZnO NPs size might conversely decrease their toxicities. ${ }^{19,29}$ Positively charged NPs could exert higher immunotoxicity than negatively charged NPs due to effective interaction with the negative charge of acidic acid on the surface of macrophages. ${ }^{30}$ However, these studies ${ }^{27,28}$ failed to address whether immunotoxicity of ZnO NPs would be affected by the size and/or charge and whether this immunotoxicity could be categorize as immunostimulation and/or immunosuppression.

In this study, we explored the in vitro potential immunotoxicity of ZnO NPs on Raw 264.7 cells, and the systemic in vivo immunotoxicity of $\mathrm{ZnO}$ NPs using C57BL/6 mice. Further, we investigated the role of size and charge in $\mathrm{ZnO}$ NP-induced immunotoxicity.

\section{Material and methods Preparation of particle suspensions}

$\mathrm{ZnO}$ (ZnO-310, Lot No 141319) was purchased from Sumitomo Osaka Cement Co, Ltd, (Tokyo, Japan). ZnO ${ }^{\mathrm{AE} 100}$ (Zn-OX-01-NP.100N, Lot No 1871511079-673) was purchased from American Elements (Los Angeles, CA, USA). The $\mathrm{ZnO}$ NPs used in this study were sized at $20 \mathrm{~nm}\left(\mathrm{ZnO}^{\mathrm{SM} 20}\right.$, Sumitomo Osaka Cement Co, Ltd) and $100 \mathrm{~nm}\left(\mathrm{ZnO}^{\mathrm{AE} 100}\right.$;
American Elements), with approximately 99.5\% purity, milky white color, and nearly spherical shape. According to the manufacturer information, the actual size and zeta potential of the $\mathrm{ZnO}$ NPs used in this study were as follows: $29 \pm 3 \mathrm{~nm},-44.4 \pm 1 \mathrm{mV}\left(\mathrm{ZnO}^{\text {SM20(-) }}\right) ; 35 \pm 5 \mathrm{~nm}, 26.3 \pm 0.5 \mathrm{mV}$ $\left(\mathrm{ZnO}^{\mathrm{SM} 20(+)}\right) ; 72 \pm 11 \mathrm{~nm},-41.6 \pm 0.6 \mathrm{mV}\left(\mathrm{ZnO}^{\mathrm{AE} 100(-)}\right)$; and $79 \pm 12 \mathrm{~nm}, 26.1 \pm 0.4 \mathrm{mV}\left(\mathrm{ZnO}^{\mathrm{AE} 100(+)}\right)$. The surface charge (zeta potential) was modified with coating reagents, citrate to make the ZnO NPs negatively charged and L-serine to make them positively charged, as reported previously. ${ }^{31}$ In brief, $20 \mathrm{mg}$ dry powder of ZnO NPs was dissolved into $100 \mathrm{~mL}$ of L-serine/HEPES (4-(2-hydroxyethyl)-1piperazineethanesulfonic acid) $\mathrm{pH} 6.2$, and citrate/HEPES $\mathrm{pH} 7.3$ to make the NP surfaces electrostatically charged. Indicated buffers were made as follows: for the positive charge buffer, $99 \mathrm{~mL}$ of $20 \mathrm{mM}$ HEPES pH 6, L-serine ( $1 \mathrm{~g}$ ) adjusted to $\mathrm{pH} 6.2$, and for the negative charge buffer, $99 \mathrm{~mL}$ of $20 \mathrm{mM}$ HEPES $\mathrm{pH} 7$, sodium citrate ( $1 \mathrm{~g}$ ) adjusted to $\mathrm{pH}$ 7.3. Subsequently, the $\mathrm{ZnO} N P$ suspension was vortexed for 5 minutes at room temperature and then kept at $4^{\circ} \mathrm{C}$ until use. Before using, the suspension was sonicated at $4^{\circ} \mathrm{C}$ for 10 minutes with a sonicator (Hielscher-Ultrasound Technology, Teltow, Germany).

\section{Cell culture}

Raw 264.7, mouse macrophage cell line (American Type Culture Collection [ATCC], Manassas, VA, USA) was maintained in Dulbecco's Modified Eagle's Medium (DMEM; Hyclone Laboratories, Inc., South Logan, UT, USA) supplemented with $10 \%$ heat-activated fetal bovine serum (FBS, Hyclone Laboratories Inc.) and $1 \%$ antibiotic-antimycotic $\left(\mathrm{Gibco}^{\circledR}\right.$, Invitrogen Corporation, Carlsbad, CA, USA) at $37^{\circ} \mathrm{C}$ in a $5 \% \mathrm{CO}_{2}$ incubator.

\section{In vitro cell viability study}

A commercially available cell viability assay Cell Counting Kit-8 (CCK-8; Dojindo Molecular Technologies, Inc., Rockville, MD, USA) was employed to evaluate the cytotoxic effect of ZnO NPs. Approximately $1 \times 10^{5}$ of Raw 264.7 cells was seeded into 96 -well plates then incubated with various concentrations of $\mathrm{ZnO} N$ Ps for 24 hours at $37^{\circ} \mathrm{C}$ in a $5 \% \mathrm{CO}_{2}$ incubator. Cells not treated with $\mathrm{ZnO}$ NPs served as a control well in the experiment. Non-modified zinc chloride $\left(\mathrm{ZnCl}_{2}\right)$ dissolved in $1 \mathrm{X}$ phosphate buffered saline (PBS) was used as a control, without modification of surface. Afterwards, $10 \mu \mathrm{L}$ of CCK-8 solution was added to each well, incubated for 1 hour, and then absorbance was determined at $450 \mathrm{~nm}$ by a DTX- 880 multimode microplate reader (Beckman Coulter, Fullerton, 
CA, USA). The percentage of cell viability was calculated by the following formula: cell viability $(\%)=($ mean absorbency in test wells $) /($ mean absorbency in control wells $) \times 100$. All experiments were performed in triplicate.

\section{Maintenance of animals and $\mathrm{ZnO}$ NP treatment}

Six-week-old inbred C57BL/6 mice $(n=5)$ were purchased from Orient Bio Inc. (Seongnam, South Korea) and were maintained in a pathogen-free condition, and fed with a standard commercial diet. Mice were randomly assigned into five groups: normal control group, which was PBS treated, and four experimental groups treated with four types of $\mathrm{ZnO}$ NPs. Briefly, the ZnO NP suspension was orally administered in the mice with the dosage of $750 \mathrm{mg} / \mathrm{kg}$ every day continuously for 14 days. All experiments were approved by the Institutional Animal Care and Use Committee (IACUC) at Wonju College of Medicine, Yonsei University.

\section{Induction and evaluation of delayed-type hypersensitivity (DTH)}

Mice were orally administered with $750 \mathrm{mg} / \mathrm{kg}$ of different sized and charged ZnO NPs for 2 weeks. DTH assays were performed 4 days before sacrifice. To assess DTH response, mice were subcutaneously injected in the left footpad with $20 \mu \mathrm{L}$ of saline as a control, and in the right footpad with $20 \mu \mathrm{L}$ of $\mathrm{ZnO}$ NP suspension. At the indicated times after challenge (24 hours and 48 hours), footpad thickness was measured with a digital caliper (Mitutoyo Corporation, Tokyo, Japan). The level of the DTH response was determined as the difference between the left and right footpad.

\section{Preparation of splenocytes}

To isolate splenocytes, the spleen was removed aseptically from $\mathrm{C} 57 \mathrm{BL} / 6$ mice at the endpoint treatment and was placed in a tube containing $1 \times$ PBS on ice. Splenocyte suspensions were prepared by gently pressing the spleen between the frosted ends of two sterile microscope slides into a $100 \mathrm{~mm}$ tissue culture grade petri dish. The slides were rinsed at regular intervals with $1 \times$ PBS. Cell suspensions were filtered by a sterile plastic strainer and then centrifuged at 1,500 rpm for 3 minutes. For optimal lysis of erythrocytes, the pellets were resuspended in $5 \mathrm{~mL}$ red blood cell lysis buffer and incubated on ice for 5 minutes with occasional shaking. The reaction was stopped by diluting the lysis buffer with $25 \mathrm{~mL}$ of $1 \times$ PBS. Thereafter, the cells were spun $\left(1,500 \mathrm{rpm}\right.$ at $4^{\circ} \mathrm{C}$ for 5 minutes), and the supernatant was carefully removed. The pellet was then washed two times in 1X PBS and resuspended in Roswell Park Memorial Institute (RPMI)-1640 supplemented with 3\% FBS (Hyclone Laboratories Inc.) and 1\% antibiotic-antimycotic (Invitrogen Corporation). Cells were then counted. The viability of the cells used in all the experiments was higher than $95 \%$, as measured by the trypan blue exclusion method (Sigma-Aldrich, St Louis, MO, USA).

\section{Splenocyte proliferative responses to concanavalin A (Con A) and lipopolysaccharide (LPS)}

Splenocytes were seeded at $1 \times 10^{5}$ cells per well into a 96-well, flat-bottom microtiter plate in $100 \mu \mathrm{L}$ RPMI-1640 (Hyclone Laboratories, Inc.) supplemented with 10\% heatactivated FBS (Hyclone Laboratories Inc.) and 1\% antibiotic/ antimycotics. Thereafter, $1.25 \mu \mathrm{g} / \mathrm{mL}$ Con A (Sigma-Aldrich, St Louis, MO, USA) and $500 \mu \mathrm{g} / \mathrm{mL}$ of LPS (Sigma-Aldrich) were used. The plates were incubated at $37^{\circ} \mathrm{C}$ in a humidified atmosphere under $5 \% \mathrm{CO}_{2}$ for 6 hours. Cell proliferation was evaluated using a CCK-8 (Dojindo Molecular Technologies, Inc.) according to the manufacturer's instructions. Absorbance was measured at $450 \mathrm{~nm}$ by a DTX-880 multimode microplate reader (Bechman Counter Inc.).

\section{Cytotoxicity assay of natural killer (NK)-cells}

NK-enriched murine splenocytes were used as effector cells, and YAC-1 (ATCC) as target cells. Briefly, various effector cell dilutions were prepared: $1 \times 10^{6}$ cells/well for $100: 1$, $5 \times 10^{5}$ cells/well for $50: 1$, and $2.5 \times 10^{5}$ cells/well for $25: 1$. A constant number of target cells $\left(1 \times 10^{3}\right.$ cells/well $)$ were then co-cultured with the different effector cell dilutions prepared in a 96-well plate to test several effector/target cell ratios. The final combined volume was $100 \mu \mathrm{L} /$ well. The effector/target cells were incubated 6 hours at $37^{\circ} \mathrm{C}$ humidified incubator with $5 \% \mathrm{CO}_{2}$. The cytotoxic activity of NK-cells was assessed by a Cytotox 96 non-radioactive cytotoxicity assay (Promega Corporation, Fitchburg, WI, USA). Briefly, $50 \mu \mathrm{L}$ supernatant from the cell culture was collected and was moved to the new 96-well round-bottom plate. Then, $50 \mu \mathrm{L}$ of the lactate dehydrogenase (LDH) substrate mixture was added to each well and incubated for 30 minutes at room temperature, protected from light. The LDH that was released upon cell lysis was measured in the supernatant by optical density (OD) measurement at $490 \mathrm{~nm}$. Target cell lysis was calculated as: (OD of sample - OD with spontaneous release of LDH from target cells - OD with spontaneous release of LDH from effector cells $) \times 100 /(O D$ with maximal release of LDH from target cells - OD with spontaneous release of 
LDH from target cells). All experiments were performed in triplicate.

\section{Immunophenotyping of splenocytes}

Specific leukocyte subtypes of cells derived from mouse spleen were also determined by immunofluorescent antibody staining and analyzed with flow cytometry. Lymphocyte subpopulations were identified and gated using forward versus side scatter characteristics. All monoclonals were directly conjugated and were obtained from BD Biosciences (San Jose, CA, USA). Th cells (CD4+), cytotoxic T-cells (CD8+), T-cells (PE-CD4+, FITC-CD8+), B-cells (PE-CD19+, FITC-B220[CD45R+]), NK-cells (CD16+), macrophages (PE-CD11b+; FITC-CD14+), and monocytes (CD14+) were identified using the anti-mouse antibodies. Thereafter, approximately $5 \times 10^{5}$ cells were resuspended in flow cytometry buffer ( $2 \%$ FBS, $0.02 \%$ sodium azide in PBS) containing Fc-block to reduce nonspecific antibody binding. Cells were then incubated in the dark with the appropriate fluorochrome-conjugated antibody $(10 \mu \mathrm{L}$ of $1 \mu \mathrm{g} / \mathrm{mL})$ for 30 minutes at $4^{\circ} \mathrm{C}$. Afterwards, cells were washed twice with $500 \mu \mathrm{L}$ FACS (fluorescence activated cell sorter) buffer, and flow cytometry analysis was performed on the Cytomics ${ }^{\mathrm{TM}}$ FC 500 Flow Cytometer (Beckman Coulter). Control samples were matched for each fluorochrome. Data were analyzed using Modfit LT 3.2 (Verity Software House, Topsham, ME, USA) software.

\section{Measurement of nitric oxide (NO)}

NO production in the primary splenocyte culture medium was quantified spectrophotometrically using the Griess reagent G2930 (Promega Corporation). The nitrite $\left(\mathrm{NO}_{2}^{-}\right)$ present in the supernatant of splenocytes was used as an indicator of NO. Nitrite is a stable degradation product of NO. Briefly, $50 \mu \mathrm{L}$ of the splenocyte supernatant was mixed with an equal volume of Griess reagent in a 96-well roundbottom microtiter plate and incubated at room temperature for 15 minutes. The absorbance at $540 \mathrm{~nm}$ was measured, and the NO concentration was determined using a calibration curve, with sodium nitrite as a standard chemical.

\section{Measurement of serum cytokine level}

The level of the cytokines (interleukin [IL]-1 $\beta$, IL-6, tumor necrosis factor [TNF]- $\alpha$, interferon [IFN]- $\gamma$, IL-12p70, and IL-10) in serum was determined using Multiplex Bead Suspension Array System (Bio-Rad Laboratories, Hercules, CA, USA). The cytokine multiplex bead suspension array kit was purchased from Bio-Rad Laboratories. Briefly, each set of premixed beads coated with the target antibodies was added to a well, and incubated with the sample in a 96-well round-bottomed microtiter plate to react with specific analytes. Then, premixed detection antibodies were added to the wells followed by a fluorescently labeled reporter molecule that specifically binds the analyte. Standard curves for each cytokine were generated using the standard control concentrations provided in the kit. Each step requires specific incubation time, with shaking at room temperature and washing steps. All washes were performed using a Bio-Plex Pro ${ }^{\text {TM }}$ (Bio-Rad Laboratories) wash station. Finally, the samples were then read using the Bio-Plex suspension array reader, and data acquisition and analysis were carried out with the five-parameter logistic method.

\section{Statistical analysis}

All data are presented as the mean \pm standard error of the mean. The mean values among different groups were analyzed and compared using one-way analysis of variance (ANOVA) followed by subsequent multiple comparison test (Tukey) with Graph Prism (GraphPad Software, La Jolla, CA, USA) version 5.0 software packages. One-way ANOVA with repeated measurements followed by Tukey's test was applied to test the influence of ZnO NPs on bodyweight gain. A $P \leq 0.05$ was considered to be statistically significant.

\section{Results}

\section{Cell viability study}

The influence of $\mathrm{ZnO}$ NP size and charge on immune cells remains unclear. To clarify this, using four types of $\mathrm{ZnO}$ NPs, we examined in vitro cell viability. The effect of $\mathrm{ZnO}$ NPs on the viability of Raw 264.7 cells was examined using CCK-8 assay, and $\mathrm{ZnCl}_{2}$ was used as a positive control group (Figure 1). ZnO NPs at the concentrations $0-5 \mu \mathrm{g} / \mathrm{mL}$ had minimal effect on the viability of Raw 264.7 cells, although they significantly reduced the viability at a higher concentration range $(10-80 \mu \mathrm{g} / \mathrm{mL})$ after 24 hours incubation. To compare the potency of each $\mathrm{ZnO} \mathrm{NP}$, the half maximal effective concentration $\left(\mathrm{EC}_{50}\right)$ value was calculated according to sigmoidal dose-response regression (Table 1). The range of $\mathrm{EC}_{50}$ of $\mathrm{ZnO}$ NPs was $6.584-8.413 \mu \mathrm{g} / \mathrm{mL}: \mathrm{ZnO}^{\mathrm{AE} 100(+)}$ exerted the highest cytotoxicity against Raw 264.7 cells $\left(\mathrm{EC}_{50}=7.499 \mu \mathrm{g} / \mathrm{mL}\right)$, while the cytotoxicity strength of other $\mathrm{ZnO}$ NPs was $\mathrm{ZnO}^{\mathrm{AE} 100(-)}>\mathrm{ZnO}^{\mathrm{SM} 20(+)}>\mathrm{ZnO}^{\mathrm{SM} 20(-)}>$ $\mathrm{ZnCl}_{2}$ in descending order. Of note, $\mathrm{ZnCl}_{2}$ was less cytotoxic than $\mathrm{ZnO}$ NPs $\left(\mathrm{EC}_{50}=14.82 \mu \mathrm{g} / \mathrm{mL}\right)$. Additionally, $\mathrm{EC}_{50}$ values of $100 \mathrm{~nm}$-sized $\mathrm{ZnO}$ NPs were higher than those of 
A

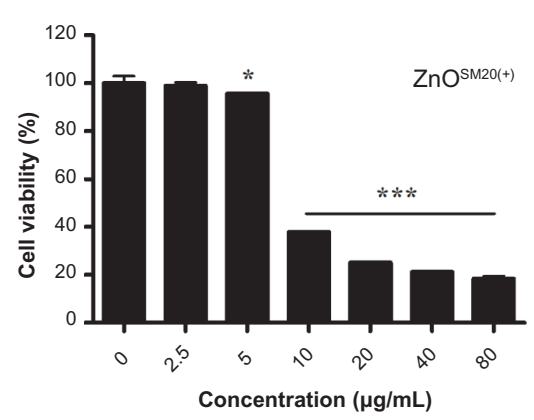

C

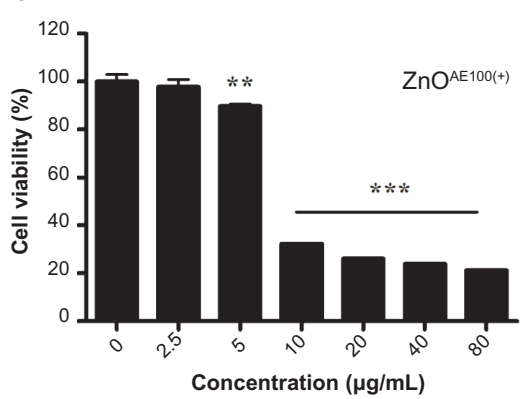

B

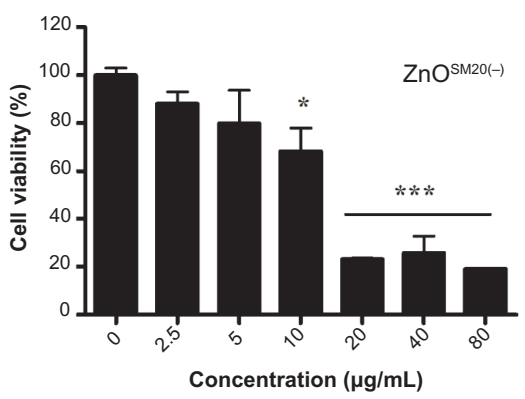

D

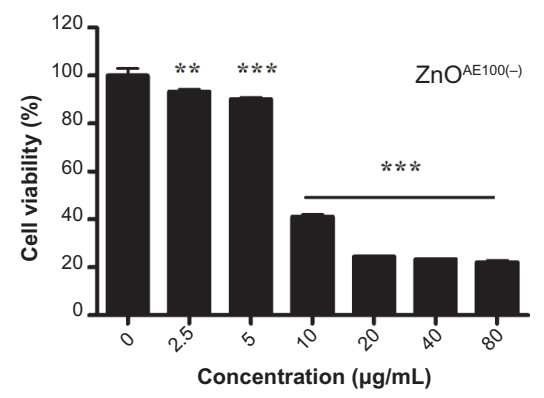

E

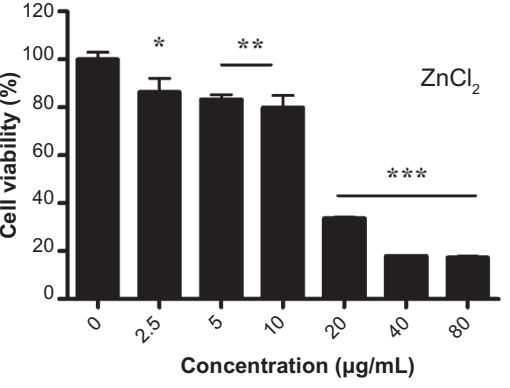

Figure I Effect of different sized and electrostatically charged ZnO NPs on the viability of Raw 264.7 cells. Cells were incubated, with indicated concentrations of ZnO NPs for 24 hours: (A) $\mathrm{ZnO}^{\mathrm{SM20(+)}}$, (B) $\mathrm{ZnO}^{\mathrm{SM20(-)}}$, (C) $\mathrm{ZnO}^{\mathrm{AEI} 100(+)}$, (D) $\mathrm{ZnO}^{\mathrm{AEI} 100(-)}$, and (E) $\mathrm{ZnCl}_{2}$. DMEM media was used as a negative control. Cell viability was then determined by a CCK-8 assay.

Notes: All values are presented as mean \pm SEM of three experiments conducted in triplicate. Percentages were also calculated in reference to the control well $(0)$. $* P<0.05$; $* * P<0.0$ I, and $* * * P<0.00$ I versus control well (0). AE = American Elements (Los Angeles, CA, USA); CCK-8 = Cell Counting Kit-8 (Dojindo Molecular Technologies, Inc., Rockville, MD, USA); SM = Sumitomo Osaka Cement Co, Ltd, (Tokyo, Japan).

Abbreviations: DMEM, Dulbecco's Modified Eagle's Medium; NP, nanoparticle; SEM, standard error of the mean; $\mathrm{ZnCl}_{2}$, zinc chloride; $\mathrm{ZnO}$, zinc oxide.

20 nm-sized ZnO NPs. Moreover, positively charged NPs showed higher cytotoxicity compared with their positively charged counterpart, suggesting that the size and charge of ZnO NPs could affect their cytotoxicity.

\section{Immunophenotyping}

$\mathrm{ZnO}$ NP treatment slightly induced the alteration in cell distribution of splenocytes (Table 2). While Th (CD4+) and cytotoxic $\mathrm{T}(\mathrm{CD} 8+)$ cells accounted for $16.6 \%$ and $9.1 \%$, respectively, of the control, the distribution of $\mathrm{Th}$ cells and cytotoxic T-cells in splenocytes of treated groups $\left(\mathrm{ZnO}^{\mathrm{SM} 20(+/-)}, \mathrm{ZnO}^{\mathrm{AE} 100(+/-)}\right)$ was changed to $14.66 \% / 9.18 \%$, $15.44 \% / 11.62 \%, 14.53 \% / 10.22 \%, 16.80 \% / 11.60 \%$, respectively. Notably, the percentage of Th cells was signifi- cantly reduced when treated with $\mathrm{ZnO}^{\mathrm{AE} 100(+)}$ as compared with control (Table 2). Moreover, the ratio of CD4+ T-cells to CD8+ T-cells, which are subpopulations of T-cells (Th cells and cytotoxic T-cells), significantly changed from 1.634-fold to 1.301-fold in $\mathrm{ZnO}^{\mathrm{AE} 100(+)}$-fed mice. However, little differences were noted in the proportion of B-cell, NK-cell, macrophage, and monocyte subpopulations.

\section{Innate, cell-mediated immune response (DTH and mitogenic response) against $\mathrm{ZnO} N P s$}

To assess the effect of $\mathrm{ZnO}$ NPs on regulation of innate immune response, NK-cell activity was examined using NK-sensitive YAC-1 target cells. As shown in Figure 2,

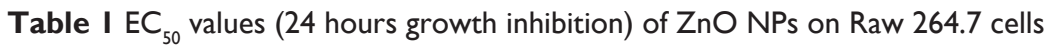

\begin{tabular}{|c|c|c|c|c|c|}
\hline & \multicolumn{4}{|l|}{ ZnO } & \multirow[t]{2}{*}{$\mathrm{ZnCl}_{2}$} \\
\hline & SM20(+) & SM20(-) & AEIO0(+) & AEIOO(-) & \\
\hline $\mathrm{EC}_{50}(\mu \mathrm{g} / \mathrm{mL})$ & 8.419 & 10.710 & 7.499 & 8.166 & 14.820 \\
\hline $95 \%$ confidence limit $(\mu \mathrm{g} / \mathrm{mL})$ & 7.109-9.730 & $5.087-16.330$ & $6.584-8.413$ & $7.124-9.207$ & $8.866-20.780$ \\
\hline
\end{tabular}

Notes: All values are presented as mean \pm SEM of the three experiments conducted in triplicate; $(+)$, positive charge; $(-)$, negative charge. AE $=$ American Elements $($ Los Angeles, CA, USA); SM = Sumitomo Osaka Cement Co, Ltd, (Tokyo, Japan).

Abbreviations: $\mathrm{EC}_{50}$, half maximal effective concentration; NP, nanoparticle; SEM, standard error of the mean; $\mathrm{ZnCl}$, zinc chloride; $\mathrm{ZnO}$, zinc oxide. 
Table 2 Immunophenotype of splenocytes in C57BL/6 mice fed with ZnO NPs for 14 days

\begin{tabular}{|c|c|c|c|c|c|}
\hline Administration & PBS & $\mathrm{ZnO}^{\mathrm{SM} 20(+)}$ & $\mathrm{ZnO}^{\mathrm{SM} 20(-)}$ & ZnOAE $100(+)$ & $\mathrm{ZnO}^{\mathrm{AE} 100(-)}$ \\
\hline $\mathrm{CD}^{+} \mathrm{CD}^{-\mathrm{a}}$ & $16.60 \pm 0.60$ & $14.66 \pm 0.80$ & $15.44 \pm 0.54$ & $14.53 \pm 1.37^{*}$ & $16.80 \pm 0.69$ \\
\hline $\mathrm{CD} 4^{-} \mathrm{CD} 8^{+\mathrm{b}}$ & $9.10 \pm 1.18$ & $9.18 \pm 0.42$ & $11.62 \pm 0.53$ & $10.22 \pm 0.64$ & $11.60 \pm 0.33$ \\
\hline $\mathrm{CD}^{+}{ }^{+} \mathrm{CD} 8^{+c}$ & $0.40 \pm 0.04$ & $0.32 \pm 0.04$ & $0.32 \pm 0.04$ & $0.38 \pm 0.11$ & $0.28 \pm 0.05$ \\
\hline $\mathrm{B}^{2} 20^{+} \mathrm{CD} 19^{-}$ & $0.78 \pm 0.09$ & $0.68 \pm 0.04$ & $0.80 \pm 0.07$ & $0.83 \pm 0.09$ & $0.60 \pm 0.03$ \\
\hline $\mathrm{B} 220^{-} \mathrm{CD} 19^{+}$ & $8.70 \pm 1.09$ & $7.82 \pm 0.38$ & $7.20 \pm 0.42$ & $9.02 \pm 1.32$ & $5.98 \pm 2.23$ \\
\hline $\mathrm{B} 220^{+} \mathrm{CD} 19^{+\mathrm{d}}$ & $51.58 \pm 1.56$ & $51.78 \pm 2.52$ & $53.70 \pm 0.54$ & $53.50 \pm 0.55$ & $52.92 \pm 1.04$ \\
\hline $\mathrm{CDI}^{+\mathrm{e}}$ & $58.55 \pm 1.30$ & $59.02 \pm 2.26$ & $59.88 \pm 0.53$ & $55.44 \pm 6.69$ & $58.76 \pm 1.17$ \\
\hline $\mathrm{CDII} \mathrm{b}^{+} \mathrm{CD} / 4^{-}$ & $6.80 \pm 0.27$ & $6.54 \pm 0.22$ & $6.80 \pm 0.34$ & $6.52 \pm 0.71$ & $5.56 \pm 0.23$ \\
\hline $\mathrm{CDIIb}^{-} \mathrm{CD} / 4^{+}$ & $0.25 \pm 0.03$ & $0.42 \pm 0.06$ & $0.26 \pm 0.06$ & $0.30 \pm 0.03$ & $0.30 \pm 0.04$ \\
\hline $\mathrm{CD} \mathrm{Ib} \mathrm{b}^{+} \mathrm{CD} \mid 4^{+f, g}$ & $1.23 \pm 0.06$ & $1.04 \pm 0.07$ & $1.04 \pm 0.12$ & $1.50 \pm 0.21$ & $0.94 \pm 0.07$ \\
\hline
\end{tabular}

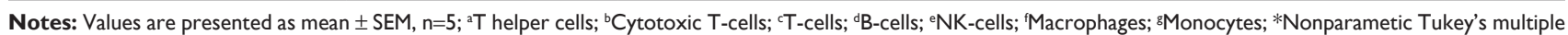
comparison test, $P<0.05$ versus PBS. AE = American Elements (Los Angeles, CA, USA); SM = Sumitomo Osaka Cement Co, Ltd, (Tokyo, Japan).

Abbreviations: NP, nanoparticle; PBS, phosphate buffered saline; SEM, standard error of the mean; ZnO, zinc oxide.

a decrease of NK-cell activity was observed in the mice treated with ZnO NPs. At the ratio of 100:1, ZnO NPs significantly inhibited NK-cell activity. Next, we examined the effect of ZnO NPs on cell-mediated immunity (CMI) using DTH response on C57BL/6 mice. The swelling volume was similar after 24-hour and 48-hour challenges (Table 3). An increased DTH response to ZnO NPs was observed. However these differences were not statistically significant. Further, we analyzed the mitogen-stimulated proliferative responses of T- and B-lymphocytes (Figure 3). These responses were elevated compared with control but not significant. Taken together, ZnO NPs affected NK activity but not CMI.

\section{NO production of splenocytes}

$\mathrm{NO}$ is a reactive form of nitrogen and is an important cellular signaling molecule involved in several biological processes, and moreover, serves as one of the key mediators of immune defense. To further explore the impact of $\mathrm{ZnO}$ NPs

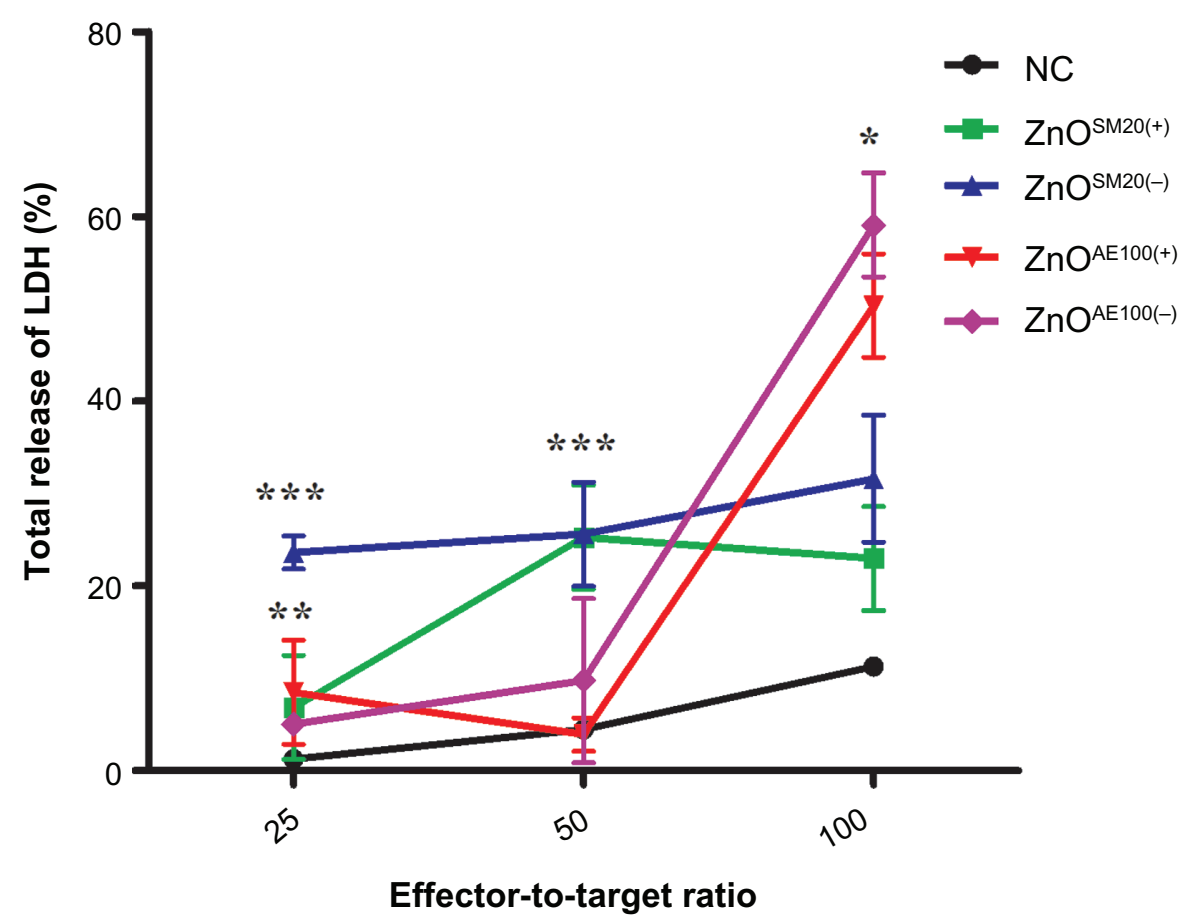

Figure 2 Effects of ZnO NP treatment on NK-cell activity. Effector cells (NK-cells) were isolated from the spleen of mice fed with a $750 \mathrm{mg} / \mathrm{kg}$ dose of ZnO NPs for 14 days. YAC-I cells were used as target cells. ZnO NP treatment reduced NK-cell cytotoxicity in the treated groups compared with control.

Notes: Values are presented as mean \pm SEM of percentage cytotoxicity, $n=5$. $* P<0.05$; $* * P<0.01$, and $* * * P<0.00$ I. AE $=$ American Elements (Los Angeles, CA, USA); SM = Sumitomo Osaka Cement Co, Ltd, (Tokyo, Japan).

Abbreviations: LDH, lactate dehydrogenase; NC, normal control; NK, natural killer; NP, nanoparticle; SEM, standard error of the mean; ZnO, zinc oxide. 
Table 3 Delayed type hypersensitivity in ZnO NP-primed mice

\begin{tabular}{|c|c|c|c|c|}
\hline \multirow[t]{3}{*}{ Treatment } & \multicolumn{4}{|c|}{ Foot-pad swelling (mm) } \\
\hline & \multicolumn{2}{|c|}{24 hours } & \multicolumn{2}{|l|}{48 hours } \\
\hline & Saline & ZnO NPs & Saline & ZnO NPs \\
\hline $\mathrm{ZnO}^{\mathrm{SM} 20(+)}$ & $6.780 \pm 1.484$ & $7.242 \pm 1.318$ & $6.8230 \pm 0.3485$ & $7.8120 \pm 0.7510$ \\
\hline $\mathrm{ZnO}^{\text {SM20(-) }}$ & $1.5230 \pm 0.9862$ & $1.202 \pm 1.103$ & $1.5570 \pm 0.3313$ & $1.7060 \pm 0.5497$ \\
\hline $\mathrm{ZnO} \mathrm{AEIO0(+)}^{\mathrm{A}}$ & $10.5500 \pm 0.4293$ & $11.700 \pm 2.053$ & $7.1400 \pm 0.6409$ & $10.480 \pm|.52|$ \\
\hline $\mathrm{ZnO}^{\mathrm{AE} 100(-)}$ & $4.3170 \pm 0.8631$ & $4.718 \pm 1.730$ & $1.3400 \pm 0.7702$ & $1.3380 \pm 0.6657$ \\
\hline
\end{tabular}

Notes: Measurement of footpad swelling in mice induced by DTH response after 24 -hour and 48-hour challenges. Values are presented as mean \pm SEM, $n=5$. AE $=$ American Elements (Los Angeles, CA, USA); SM = Sumitomo Osaka Cement Co, Ltd, (Tokyo, Japan).

Abbreviations: DTH, delayed-type hypersensitivity; NP, nanoparticle; SEM, standard error of the mean; ZnO, zinc oxide.

on immune defense, we measured the level of splenic NO production after 14 days treatment. As shown in Figure 4, a significant decrease in NO level occurred after administration of $\mathrm{ZnO}^{\mathrm{SM} 20(-)}$ and $\mathrm{ZnO}^{\mathrm{AE} 100(+/)}$. However, there was no substantial difference of $\mathrm{NO}$ level in $\mathrm{ZnO}^{\mathrm{SM} 20(+)}$-fed mice as compared with the control.

\section{Serum cytokine level}

To explore immune status change induced by ZnO NPs we examined serum pro- and anti-inflammatory cytokine (IL- $1 \beta$, IL-6, TNF- $\alpha$, IL-12p70, IFN- $\gamma$, and IL-10) levels at the endpoint treatment. We found that overall, the level of serum cytokines in $\mathrm{ZnO}$-fed mice was lower than saline-fed mice (Figure 5). In particular, serum levels of pro-inflammatory cytokines (IL-1 $\beta$, TNF- $\alpha$, and IL-12p70) in ZnO NP-fed mice were $\mathrm{ZnO}^{\mathrm{SM} 20(+)}>\mathrm{ZnO}^{\mathrm{SM} 20(-)}>\mathrm{ZnO}^{\mathrm{AE} 100(+)}>\mathrm{ZnO}^{\mathrm{AE} 100(-)}$ in descending order. Accordingly, the level of IL-10, an antiinflammatory cytokine in ZnO NP-fed mice tended to be significantly lower than PBS-fed mice. By contrast, there was no significant change of cytokine level in $\mathrm{ZnO}^{\mathrm{SM} 20(+)}$-fed mice. In terms of size and charge effect on serum cytokine level, the size and charge were correlated to serum cytokine level. Further, the size appears more correlated to the serum cytokine than the charge. Taken together, our data show that oral intake of ZnO NPs in mice could drop the level of serum cytokines, importantly implying the possible suppression of immune status of C57BL/6 mice fed with $\mathrm{ZnO}$ NPs.

\section{Discussion}

Convincing evidence has shown that ZnO NPs would have a potential to be accumulated to several organs such as liver, spleen, kidneys, brain or heart after deliberately placed in the body. ${ }^{32}$ In this regard, ZnO NPs would encounter diverse immune cells in the human body, thus damaging immune tissues and organs. However, the immunotoxicity of $\mathrm{ZnO}$ NPs in relation to the size and charge of $\mathrm{ZnO}$ NPs is unclear. To address this issue, we assessed the immunotoxicity of $\mathrm{ZnO}$ NPs in vitro and in vivo and explored their underlying mechanism. First, the in vitro study indicates that ZnO NPs induce cytotoxicity to immunocytes via cell viability assay, which is influenced by the size and charge of ZnO NPs. To validate this, we examined cell viability using colorimetric (CCK-8 assay) in Raw 264.7, macrophage cell line.

Cell viability assay showed that $\mathrm{ZnO}$ NPs with different size and electrostatic charge have differential cytotoxicity to Raw 264.7 cells (Figure 1). Interestingly, the positively
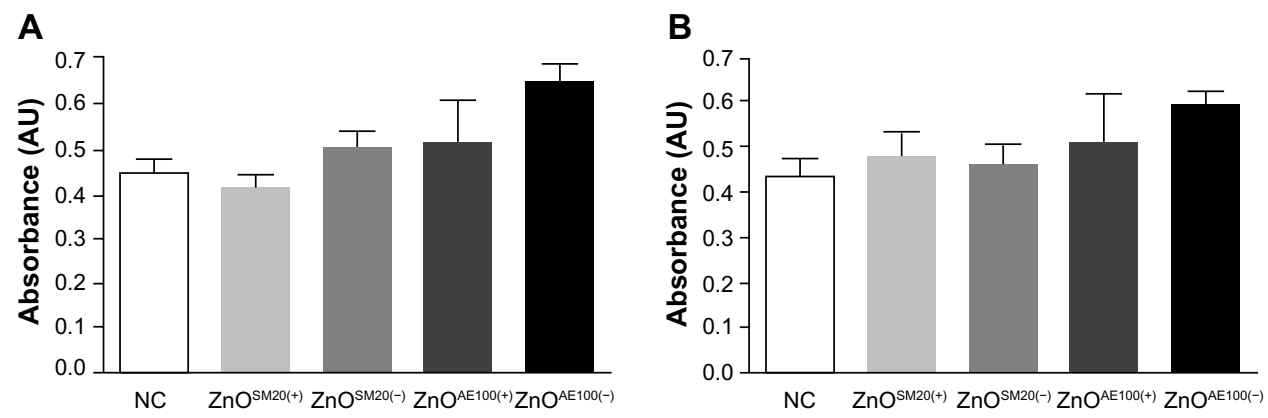

Figure 3 Mitogenic response of mouse splenocytes. Splenocytes $\left(I \times 10^{6}\right.$ cells $\left./ \mathrm{mL}\right)$ were incubated for 24 hours with concanavalin $\mathrm{A}$ or lipopolysacchride to evaluate T-lymphocyte (A) and B-lymphocyte (B) proliferation, respectively.

Notes: Values are presented as mean \pm SEM, $n=5$. AE = American Elements (Los Angeles, CA, USA); SM = Sumitomo Osaka Cement Co, Ltd, (Tokyo, Japan).

Abbreviations: NC, normal control; SEM, standard error of the mean; $\mathrm{ZnO}$, zinc oxide. 


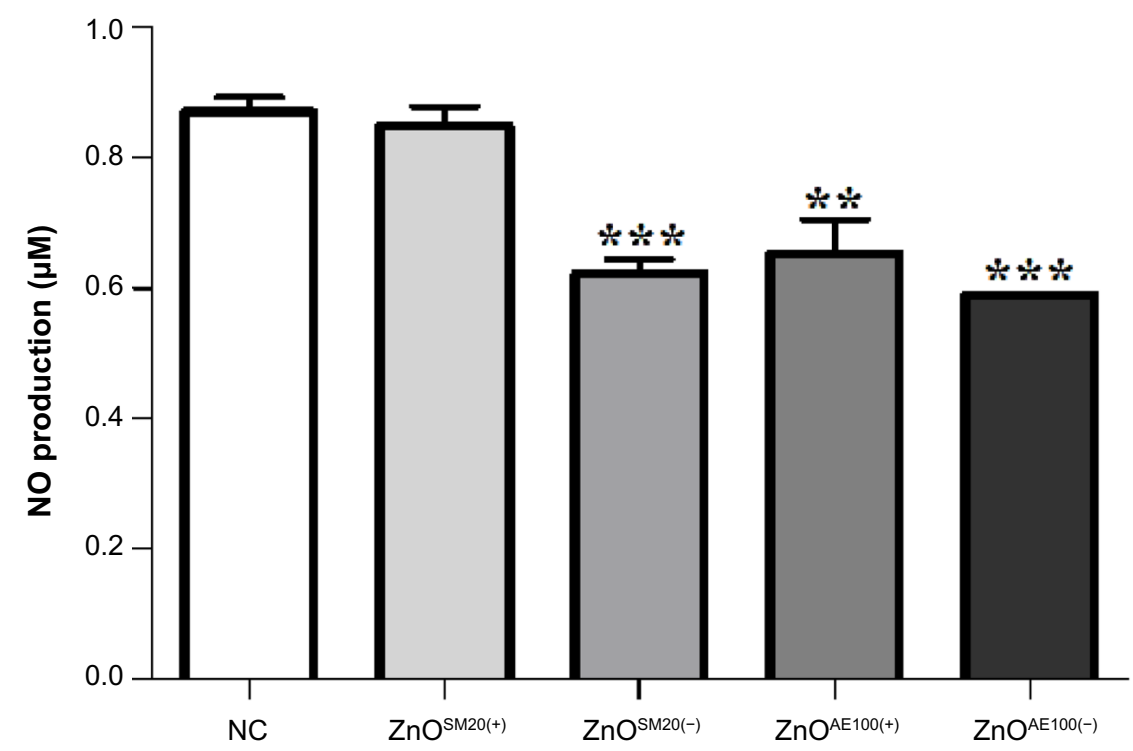

Figure 4 Detection of NO induced by ZnO NPs on mouse splenocytes. Splenocytes were isolated and cultured. NO production in the supernatant was measured by the Griess reaction.

Notes: Values are presented as mean $\pm \mathrm{SEM}, \mathrm{n}=5$. $* * \mathrm{p}<0.01$, and $* * * \mathrm{p}<0.001$. AE = American Elements (Los Angeles, CA, USA); SM $=$ Sumitomo Osaka Cement Co, Ltd, (Tokyo, Japan).

Abbreviations: NC, normal control; NO, nitric oxide; NP, nanoparticle; SEM, standard error of the mean; ZnO, zinc oxide.

charged NPs exerted higher cytotoxicity against Raw 264.7 cells than the negatively charged ones. ZnO NP-induced cytotoxicity could be affected by the release of $\mathrm{Zn}^{2+}$ ions through the dissolution of $\mathrm{ZnO}$ NPs within aqueous culture media. ${ }^{33-35}$ In terms of $\mathrm{EC}_{50}$, we found that $\mathrm{ZnO} \mathrm{NPs}$ would cause cytotoxicity at lower doses (Table 1). This difference might be due to inherent features of metal oxides: free $\mathrm{Zn}^{2+}$ ions and oxidative radical-generated oxide, and $\mathrm{ZnO} \mathrm{NP}$ surface charge, would synergistically exert cytotoxicity to eukaryotic cells. In this experiment, another merit is the
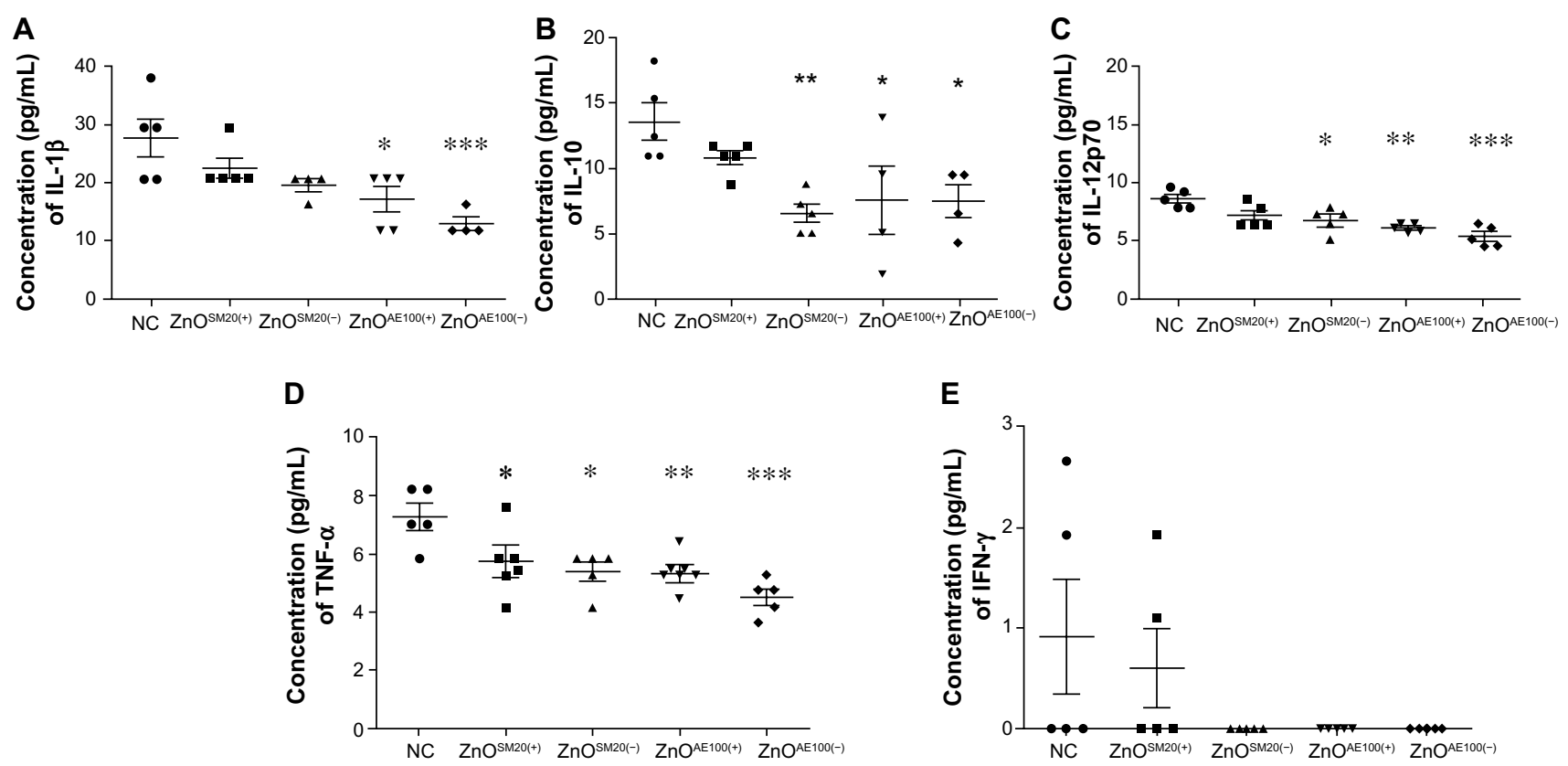

Figure $5 \mathrm{ZnO}$ NPs suppress cytokine release. After 14 days exposure, mice were retro-orbital bled, and serum was isolated by centrifugation and examined for levels of IL-I $\beta$ (A), IL-10 (B), IL-I 2p70 (C), TNF- $\alpha$ (D), and IFN- $\gamma$ (E) using Multiplex Bead Array System (Bio-Rad Laboratories, Hercules, CA, USA).

Notes: Values are presented as mean $\pm \mathrm{SEM}, \mathrm{n}=5$. $* \mathrm{P}<0.05 ; * * \mathrm{P}<0.0 \mathrm{I}$, and $* * * \mathrm{P}<0.00 \mathrm{I}$. AE = American Elements (Los Angeles, CA, USA); SM = Sumitomo Osaka Cement Co, Ltd, (Tokyo, Japan).

Abbreviations: IFN, interferon; IL, interleukin; NC, normal control; NP, nanoparticle; SEM, standard error of the mean; TNF, tumor necrosis factor; ZnO, zinc oxide. 
validity of in vitro toxicity test using the Raw 264.7 cell line. While, this cell line is a well-known standard cell line for in vitro toxicity testing, in vitro toxicity testing for nanoparticles has not been established. Collectively, we have demonstrated that macrophage Raw 264.7 cells exposed to $\mathrm{ZnO}$ NPs show different sized- and charged-dependent cytotoxicity, as was observed by others..$^{19,36,37}$ Further, the dose-dependent decrease in cell viability by exposure with $\mathrm{ZnO}$ NPs might be related to the dissolution and release of $\mathrm{Zn}^{2+}$ ions, as previously observed in in-vitro studies. ${ }^{33-35,38-40}$ This $\mathrm{Zn}^{2+}$ ion would affect cellular differentiation and cellular metabolism solely or via the interaction with proteins in vitro and in vivo.

Since, in vitro culture cannot reflect the complexity of an in vivo system, which is preferred for the toxicological evaluation, we next examined the immunotoxicological parameters induced by oral intake of $\mathrm{ZnO}$ NPs in mice. Our in vivo study indicates that the different sized- and charged$\mathrm{ZnO}$ NPs could cause immunotoxicity in $\mathrm{ZnO}$ NP-fed mice, of which nature is an immunosuppression. This stems from our immunotoxicological data. Prior to immunotoxicological evaluation, we checked the weight-related parameters (bodyweight and coefficient of spleen to bodyweight). Of these, only the reduced bodyweight gain was noted (data not shown), suggesting the potential immunotoxicity of ZnO NPs in vivo. Since in vitro data showed $\mathrm{ZnO}$-induced toxicity in immunocytes, bodyweight change coupled with in vitro data might be considered for predicting potential immunotoxicity of nanoparticles.

To explore the effect of $\mathrm{ZnO}$ NPs on the CMI, we measured the DTH reaction to $\mathrm{ZnO}$ NPs, splenocyte proliferation in response to Con A and LPS, NK-cell activity, and splenocyte phenotyping. Overall, no significant change was observed in DTH responses (Table 3) and T- and B-cell proliferation (Figure 3). By contrast, we found a slight change in splenocyte phenotypes (Table 2). Since CD4+ cells can help the proliferation and differentiation of Th cells, and CD8+ cells can exert cytotoxicity and regulate CD4+ cells, the ratio of CD4+/CD8+ can reflect the overall immune status in the host. Of note, there was the decreased percentage of CD4+ Th cell subpopulation in $\mathrm{ZnO}^{\mathrm{AE} 100(+)}$-fed mice as compared with control mice (Table 2). Consistently, the ratio of $\mathrm{CD} 4+/ \mathrm{CD} 8+$ was reduced, which might imply systemic immune suppression. These CMI variables do not reveal specific function of the innate arm in CMI. Moreover, CD16 (FcrRIII) alone can be a marker for NK, as this surface marker is shed from the surface after activation of NK-cells. ${ }^{41,42}$ Only $\mathrm{ZnO}^{\mathrm{AE} 100(+)}$-fed mice showed a decreased level of CD16 among other groups fed with $\mathrm{ZnO}$. Collective evidence showed that loss of CD16 on NK-cells is associated with reduced antibody-mediated cellular cytotoxicity and weaker antitumor response. ${ }^{43}$ Therefore, levels of CD16 could influence NK-cell function. To address this, we checked NK-cell activity. Astonishingly, NK-cell activity at the ratio of 100:1 was significantly decreased in all ZnO NPfed mice compared with control (Figure 2) and most prominent on the $\mathrm{ZnO}^{\mathrm{AE} 100(+)}$-fed group. However, further research is needed to prove this inference, such as development of tumors. NK-cells were defined as lymphocytes mediating cytotoxicity against certain tumors and virus-infected target cells. In this point, the suppression of NK-cell activity may reveal the weakened innate defense in CMI, consequently getting vulnerable to opportunistic dangers such as infection, cancer, and stress. Given this, we hypothesized that if these data would be valid, humoral immune mediators should be co-regulated toward the immune suppression. To verify this, we selected two humoral immune parameters (NO and cytokines).

First, we checked NO production from splenocytes of $\mathrm{ZnO}$-fed mice. $\mathrm{NO}$ is a reactive nitrogen species which plays an important role in the destruction and suppression of many intracellular pathogenic organisms. ${ }^{44,45} \mathrm{NO}$ acts as an effector molecule in macrophage-mediated cytotoxicity. ${ }^{46}$ However, the NO production of macrophages was regulated and required to be optimized by $\mathrm{CD} 4+\mathrm{T}$-cells. We found that three oral intakes of $\mathrm{ZnO} N P s$, except $\mathrm{ZnO}^{\mathrm{SM} 20(+)}$, significantly decreased NO production of splenocytes (Figure 4). Viewed together, this is in line with the suppression of NK-cell activity and the ratio of CD4+/CD8+ observed.

Since NO could contribute to the regulation of immune reaction by modifying the release of cytokines, ${ }^{47-49}$ finally we quantified the serum cytokine release in $\mathrm{ZnO}$-fed mice. To further analyze the several facets of in vivo immunotoxicity in $\mathrm{ZnO}$ NP-fed mice, we selected five kinds of pro- and antiinflammatory cytokines (IL- $1 \beta$, TNF- $\alpha$, IL-12p70, IFN- $\gamma$, and IL-10). Cytokine assay showed that the overall level of serum cytokines in $\mathrm{ZnO}$-fed mice decreased as compared with control (Figure 5). Of these cytokines, in line with the concentration in serum, IL-1 $\beta$ and IL-10 were prominent in detecting the cytokine change in $\mathrm{ZnO}$ NP-fed mice. These cytokines were the representative pro- and anti-inflammatory cytokines, respectively. The decreased level of these opposite cytokines in $\mathrm{ZnO} \mathrm{NP}$-fed mice might be ascribed to nonspecific immune suppression or even an imbalance between pro- and anti-inflammatory cytokine networks. The limitation of this study is the lack of different dose usage 
in vivo. To gauge this phenomena in detail, further work is underway.

\section{Conclusion}

Synthesizing these immunotoxicological data in vivo and in vitro, our results indicate that different sized and charged $\mathrm{ZnO}$ NPs would cause in vitro and in vivo immunotoxicity, of which nature is a minor immunosuppression. This has important implications for individuals who may be chronically exposed to ZnO NPs. Further, this study might offer the possibility of the new immune parameters such as cytokine and NO for gauging immunotoxicity for nanoparticles.

\section{Acknowledgment}

This research was supported by a Grant (10182MFDS991) from the Ministry of Food and Drug Safety 2011. This work was supported by the National Research Foundation of Korea Grant funded by the Korean Government (NRF2013R1A1A2012665).

\section{Disclosure}

The authors report no conflicts of interest in this work.

\section{References}

1. Duguet E, Vasseur S, Mornet S, Devoisselle JM. Magnetic nanoparticles and their applications in medicine. Nanomedicine (Lond). 2006;1(2): 157-168.

2. Salata O. Applications of nanoparticles in biology and medicine. J Nanobiotechnology. 2004;2(1):3.

3. Sanvicens N, Marco MP. Multifunctional nanoparticles - properties and prospects for their use in human medicine. Trends Biotechnol. 2008;26(8):425-433.

4. Zhang L, Gu FX, Chan JM, Wang AZ, Langer RS, Farokhzad OC. Nanoparticles in medicine: therapeutic applications and developments. Clin Pharmacol Ther. 2008;83(5):761-769.

5. De Jong WH, Borm PJ. Drug delivery and nanoparticles: applications and hazards. Int J Nanomedicine. 2008;3(2):133-149.

6. Hanley C, Layne J, Punnoose A, et al. Preferential killing of cancer cells and activated human $\mathrm{T}$ cells using $\mathrm{ZnO}$ nanoparticles. Nanotechnology. 2008;19(29):295103.

7. Zhang H, Chen B, Jiang H, Wang C, Wang H, Wang X. A strategy for $\mathrm{ZnO}$ nanorod mediated multi-mode cancer treatment. Biomaterials. 2011;32(7):1906-1914.

8. Hooper HL, Jurkschat K, Morgan AJ, et al. Comparative chronic toxicity of nanoparticulate and ionic zinc to the earthworm Eisenia veneta in a soil matrix. Environ Int. 2011;37(6):1111-1117.

9. Jang J, Lim DH, Choi IH. The impact of nanomaterials in immune system. Immune Netw. 2010;10(3):85-91.

10. Matsumura M, Takasu N, Nagata M, Nakamura K, Kawai M, Yoshino S. Effect of ultrafine zinc oxide $(\mathrm{ZnO})$ nanoparticles on induction of oral tolerance in mice. J Immunotoxicol. 2010;7(3):232-237.

11. Pasupuleti S, Alapati S, Ganapathy S, Anumolu G, Pully NR, Prakhya BM. Toxicity of zinc oxide nanoparticles through oral route. Toxicol Ind Health. 2012;28(8):675-686.

12. Zheng YF, Li Z, Wang YD. In vitro and in vivo biocompatibility studies of Zno nanoparticles. Int J Mod Phys B. 2009;23(06-07):1566-1571.
13. Bae HC, Ryu HJ, Jeong SH, et al. Oxidative stress and apoptosis induced by $\mathrm{ZnO}$ nanoparticles in HaCaT cells. Mol Cell Toxicol. 2012;7(4):333-337.

14. Lee SH, Pie J-E, Kim Y-R, Lee HR, Son SW, Kim M-K. Effects of zinc oxide nanoparticles on gene expression profile in human keratinocytes. Mol Cellular Toxicol. 2012;8(2):113-118.

15. Heng BC, Zhao X, Tan EC, et al. Evaluation of the cytotoxic and inflammatory potential of differentially shaped zinc oxide nanoparticles. Arch Toxicol. 2011;85(12):1517-1528.

16. Roy R, Tripathi A, Das M, Dwivedi PD. Cytotoxicity and uptake of zinc oxide nanoparticles leading to enhanced inflammatory cytokines levels in murine macrophages: comparison with bulk zinc oxide. J Biomed Nanotechnol. 2011;7(1):110-111.

17. Yanagisawa $\mathrm{R}$, Takano $\mathrm{H}$, Inoue $\mathrm{K}$, et al. Titanium dioxide nanoparticles aggravate atopic dermatitis-like skin lesions in NC/Nga mice. Exp Biol Med (Maywood). 2009;234(3):314-322.

18. Liu Y, Jiao F, Qiu Y, et al. The effect of Gd@C82(OH)22 nanoparticles on the release of Th1/Th2 cytokines and induction of TNFalpha mediated cellular immunity. Biomaterials. 2009;30(23-24): 3934-3945.

19. Hanley C, Thurber A, Hanna C, Punnoose A, Zhang J, Wingett DG. The influences of cell type and $\mathrm{ZnO}$ nanoparticle size on immune cell cytotoxicity and cytokine induction. Nanoscale Res Lett. 2009;4(12): 1409-1420.

20. Heng BC, Zhao X, Xiong S, Ng KW, Boey FY, Loo JS. Toxicity of zinc oxide $(\mathrm{ZnO})$ nanoparticles on human bronchial epithelial cells (BEAS-2B) is accentuated by oxidative stress. Food Chem Toxicol. 2010;48(6):1762-1766.

21. Lipovsky A, Nitzan Y, Gedanken A, Lubart R. Antifungal activity of $\mathrm{ZnO}$ nanoparticles - the role of ROS mediated cell injury. Nanotechnology. 2011;22(10):105101.

22. Song W, Zhang J, Guo J, et al. Role of the dissolved zinc ion and reactive oxygen species in cytotoxicity of $\mathrm{ZnO}$ nanoparticles. Toxicol Lett. 2010;199(3):389-397.

23. Moos PJ, Chung K, Woessner D, Honeggar M, Cutler NS, Veranth JM. $\mathrm{ZnO}$ particulate matter requires cell contact for toxicity in human colon cancer cells. Chem Res Toxicol. 2010;23(4):733-739.

24. Sasidharan A, Chandran P, Menon D, Raman S, Nair S, Koyakutty M. Rapid dissolution of $\mathrm{ZnO}$ nanocrystals in acidic cancer microenvironment leading to preferential apoptosis. Nanoscale. 2011;3(9):3657-3669.

25. Sharma V, Anderson D, Dhawan A. Zinc oxide nanoparticles induce oxidative DNA damage and ROS-triggered mitochondria mediated apoptosis in human liver cells (HepG2). Apoptosis. 2012;17(8): 852-870.

26. Di Gioacchino M, Petrarca C, Lazzarin F, et al. Immunotoxicity of nanoparticles. Int J Immunopathol Pharmacol. 2011;24 Suppl 1: S65-S71.

27. Sohaebuddin SK, Thevenot PT, Baker D, Eaton JW, Tang L. Nanomaterial cytotoxicity is composition, size, and cell type dependent. Part Fibre Toxicol. 2010;7:22.

28. Yang H, Liu C, Yang D, Zhang H, Xi Z. Comparative study of cytotoxicity, oxidative stress and genotoxicity induced by four typical nanomaterials: the role of particle size, shape and composition. $J \mathrm{Appl}$ Toxicol. 2009;29(1):69-78.

29. Padmavathy N, Vijayaraghavan R. Enhanced bioactivity of $\mathrm{ZnO}$ nanoparticles - an antimicrobial study. Sci Tech Adv Mater. 2008;9(3): 035004.

30. Dwivedi PD, Misra A, Shanker R, Das M. Are nanomaterials a threat to the immune system? Nanotoxicology. 2009;3(1):19-26.

31. Kim K-M, Kim T-H, Kim H-M, et al. Colloidal behaviors of $\mathrm{ZnO}$ nanoparticles in various aqueous media. Toxicol Environ Health Sci. 2012;4(2):121-131.

32. Yeh TK, Chen JK, Lin CH, et al. Kinetics and tissue distribution of neutron-activated zinc oxide nanoparticles and zinc nitrate in mice: effects of size and particulate nature. Nanotechnology. 2012;23(8):085102. 
33. Cho WS, Duffin R, Howie SE, et al. Progressive severe lung injury by zinc oxide nanoparticles; the role of $\mathrm{Zn} 2+$ dissolution inside lysosomes. Part Fibre Toxicol. 2011;8:27.

34. George S, Pokhrel S, Xia T, et al. Use of a rapid cytotoxicity screening approach to engineer a safer zinc oxide nanoparticle through iron doping. ACS Nano. 2010;4(1):15-29.

35. Xia T, Kovochich M, Liong M, et al. Comparison of the mechanism of toxicity of zinc oxide and cerium oxide nanoparticles based on dissolution and oxidative stress properties. ACS Nano. 2008;2(10): 2121-2134.

36. Feltis BN, O'Keefe SJ, Harford AJ, et al. Independent cytotoxic and inflammatory responses to zinc oxide nanoparticles in human monocytes and macrophages. Nanotoxicology. 2012;6(7):757-765.

37. Baek M, Kim MK, Cho HJ, et al. Factors influencing the cytotoxicity of zinc oxide nanoparticles: particle size and surface charge. J Phys Conf Ser. 2011;304(1):012044.

38. Horie M, Fujita K, Kato H, et al. Association of the physical and chemical properties and the cytotoxicity of metal oxide nanoparticles: metal ion release, adsorption ability and specific surface area. Metallomics. 2012;4:350-360.

39. Kunzmann A, Andersson B, Thurnherr T, Krug H, Scheynius A, Fadeel B. Toxicology of engineered nanomaterials: focus on biocompatibility, biodistribution and biodegradtion. Biochim Biophys Acta. 2011;1810(3):361-373.

40. Plascencia-Villa G, Starr CR, Armstrong LS, Ponce A, Yacaman MJ. Imaging interactions of metal oxide nanoparticles with macrophage cells by ultra-high resolution scanning electron microscopy techniques. Integr Biol. 2012;4:1358-1366.
41. Hanna J, Mandelboim O. When killers become helpers. Trends Immunol. 2007;28:201-206.

42. Anderson-Wilman B, Gehrmann U, Cansu Z, et al. Effects of subtoxic concentrations of $\mathrm{TiO}_{2}$ and $\mathrm{ZnO}$ nanoparticles on human lymphocytes, dendritic cells and exosome production. Toxicol Appl Pharmacol. 2012;264(1):94-103.

43. Lowe DB, Shearer MH, Jumper CA, Bright RK, Kennedy RC. Fc gamma receptors play a dominant role in protective tumor immunity against a virus encoded tumor-specific antigen in a murine model of experimental metastases. J Virol. 2007;81(3):1313-1318.

44. Green SJ, Scheller LF, Marletta MA, et al. Nitric oxide: cytokineregulation of nitric oxide in host resistance to intracellular pathogens. Immunol Lett. 1994;43(1-2):87-94.

45. Guzik TJ, Korbut R, Adamek-Guzik T. Nitric oxide and superoxide in inflammation and immune regulation. J Physiol Pharmacol. 2003;54(4):469-487.

46. Holan V, Krulova M, Zajicova A, Pindjakova J. Nitric oxide as a regulatory and effector molecule in the immune system. Mol Immunol. 2002;38(12-13):989-995.

47. Marcinkiewicz J, Chain BM. Differential regulation of cytokine production by nitric oxide. Immunology. 1993;80(1):146-150.

48. Schwentker A, Vodovotz Y, Weller R, Billiar TR. Nitric oxide and wound repair: role of cytokines? Nitric Oxide. 2002;7(1):1-10.

49. Tavares Murta BM, Machado JS, Zaparoli M, Lara VC, Murta EF. The relationship of host immune cells, cytokine and nitric oxide production to tumor cells in ovarian carcinoma. Sao Paulo Med J 1999;117(2):87-92.
International Journal of Nanomedicine

\section{Publish your work in this journal}

The International Journal of Nanomedicine is an international, peerreviewed journal focusing on the application of nanotechnology in diagnostics, therapeutics, and drug delivery systems throughout the biomedical field. This journal is indexed on PubMed Central, MedLine, CAS, SciSearch $®$, Current Contents ${ } /$ Clinical Medicine,

\section{Dovepress}

Journal Citation Reports/Science Edition, EMBase, Scopus and the Elsevier Bibliographic databases. The manuscript management system is completely online and includes a very quick and fair peer-review system, which is all easy to use. Visit http://www.dovepress.com/ testimonials.php to read real quotes from published authors. 